\title{
Building Bridges: Constructing Social Enterprise Curriculum in the Humanities
}

\author{
Susanna Chamberlain ${ }^{1}$ \\ ${ }^{1}$ School of Humanities, Griffith University, Brisbane, Queensland, Australia \\ Correspondence: Susanna Chamberlain, School of Humanities, Griffith University, Brisbane, Queensland, \\ Australia. E-mail: s.chamberlain@griffith.edu.au
}

Received: March 23, 2013 Accepted: April 22, 2013 Online Published: May 29, 2013

doi:10.5539/hes.v3n3p90

URL: http://dx.doi.org/10.5539/hes.v3n3p90

\begin{abstract}
Creating an innovative suite of courses within the Bachelor of Arts has required the development of a complex pedagogy, particularly when the needs of the context require an interdisciplinary approach. This paper, which utilises reflection on practice as its methodology, explores the Social Enterprise core stream which has been a significant element of study since 2008. While the paper deals with some of the particular circumstances of introducing practice learning to traditional theoretical disciplines, it is most concerned with the pedagogical strength of combining inquiry based learning with problem based learning, to lead to work integrated learning, and developing reflective practice to integrate all.
\end{abstract}

Keywords: work-integrated learning, problem-based learning, inquiry-based learning, reflective practice, transdisciplinarity, social enterprise

\section{Introduction}

Innovation in programme design often requires the creation of complex pedagogical approaches in order to meet the needs of the particular situation. In the following paper, I explore the specific situation of developing a means of introducing into an existing and established arena of study an unknown and unrecognised stream of courses. The paper itself takes an innovative approach for it is based upon the principles of reflection upon practice rather than providing a standard evaluation of a program. The key issue that the paper raises is that of the use of a multi-variant pedagogy in a transdisciplinary application and what the implications are for the Humanities.

Since 2008, the School of Humanities at Griffith University has incorporated a Social Enterprise signature experience into the Bachelor of Arts. Broadly, social enterprises are distinguished by their pursuit of community wealth in the marketplace to pursue their aims. They pursue a triple bottom line of social, economic and environmental prosperity. Griffith University is located in South East Queensland, Australia and is well regarded as both a research university and for its development of highly innovative programmes. Approximately 40, 000 students are enrolled over five campuses. In the Bachelor of Arts, we also use the verb form, "socially enterprising' to invite our students to be innovative, creative and empowered, regardless of the economic sector where they find employment. Thus our work at Griffith University is underpinned by a pedagogical ethic and imperative to excite our students about their own prospects for being a part of change, based on a thorough and ongoing engagement with people and organisations in the 'real world' who are already moving and shaking.

This has meant that a curriculum has had to be developed which both presents the underlying issues and the third sector approaches and interpolates these studies into a multi-disciplinary context. This signature experience consists of six semester-long units, presented sequentially, and includes a third year professional placement in the Third Sector. The final semester capstone subject enables students to both reflect upon their experience of the degree and to plan and manage a showcase event. The first year units focus upon the development of communication and critical thinking skills, and the introduction of critical issues relevant to the Third Sector such as human rights and social justice. Alongside an initial exploration of the history and practice of the Third Sector, these first year courses are designed to incite a broader awareness of the reason for choosing a life that contributes to the wider community. The second year units are concerned with the consolidation of an ethical foundation and developing skills required in the workplace in this field.

The development of the Social Enterprise core stream has been quite an ambitious and indeed pioneering project 
and there have certainly been a number of challenges in the creation and expansion of the curriculum. This paper explores both those challenges and the responses which have been part of this program's maturity. Challenges have included such diverse elements as the need to cultivate an interdisciplinary approach, both within the specific units, and more importantly with colleagues whose primary disciplines demand specific forms and notions of rigour. On the other hand, the materials and the foundational ideas of social enterprise tended to cross a range of disciplinary boundaries. The challenge is to present a course which can integrate an array of disciplines, while developing a new and unfamiliar discourse.

Given that the program was quite unlike the other majors offered (history, film studies, sociology, Islamic studies, literature and creative writing, for example), the challenge arose as to what kind of pedagogical framework would best suit such an interdisciplinary and ultimately practical programme (Mullin, 2008). While there may be a range of possible answers to this dilemma, we have developed a hybrid inquiry/problem based learning approach which enables students to grow into self-directed learners. Other challenges have been more specifically pedagogical. An early issue was that of name recognition; at the beginning of the programme, the term "social enterprise" was largely unknown in the Australian context, and this created many difficulties.

This serial undergraduate program has offered a particular opportunity to develop specific skills and practices over time, and the challenge has been taken up with the inclusion of reflective practice in assessments over the term of the degree. The social enterprise stream serves multiple purposes. It creates and develops within the students a deep sense of social conscience, and, hopefully, a sense of capability as well.

The postgraduate research, which is emerging in a parallel development, includes such diverse topics as the significance of ecological imperatives in social enterprises, the civil society frameworks in Muslim community organisations in Australia and the conceptualization of adaptivism as creative practice amongst people with disabilities. The range of interests is wide, but centres on the fundamental issues that are dealt with in the undergraduate program: human rights, social justice and the developing third/fourth sector which is attempting to deal with those issues.

\section{Method}

Bridges span separate and often quite distinct landscape features. This paper is concerned with the bridges that have been constructed between the Humanities and a practice orientation within the Bachelor of Arts over the past five years. To explore the context of developing a social enterprise work-integrated learning experience at Griffith University, I shall look briefly at the circumstances and background of this initiative. To introduce practical learning into the very traditional research-based disciplines of the humanities has meant that there have been problems to be considered carefully and negotiated. It is useful to understand the content of the suite of courses, in order to grasp the pedagogical approach taken to manage this unusual and groundbreaking program. What I hope to show is that the social enterprise signature experience in the Bachelor of Arts has a well-developed and innovative pedagogical approach to teaching young people how to make a difference in the world.

In 2007 the Faculty of Arts at Griffith University announced the introduction of a new format for the Bachelor of Arts. From 2008, the degree would include a compulsory stream which would culminate in a Work Integrated Learning programme, primarily concerned with engaging undergraduate students in the not- for-profit or Third Sector. Students would undertake majors in the existing Fields of Study but would also have to complete six compulsory subjects which would include field placement in the final year. The decision to take this direction had been prompted by a range of circumstances, which included the university moving towards a Work Integrated Learning orientation for all degrees, and the need for greater community involvement by the Faculty of Arts.

Since 2008 almost 2000 students have undertaken at least the first year core courses, and almost two hundred BA students have graduated having completed the social enterprise signature experience. In 2009, the compulsory courses were restricted to the first year, and so the WIL component was then available to those who voluntarily chose to complete the other courses in the stream. Ongoing research is being undertaken to discern the outcomes for graduates of this programme.

The paper utilises an innovative approach. The material presented is based upon the use of reflection upon practice, a methodology that has been emerging in the social sciences and human services in the past few years (Reed-Danahey, 2002; Moon 2004; Chamberlain 2012). While the practice of autoethnography, for example, seeks to demonstrate the underlying sociological realities by the focus upon the lived experience of the writer, or the use of reflective practice in the human services offers the opportunity for the student experience to be iterated in the form of journals, this paper applies the process of reflection on practice to the pedagogical field. In line 
with the usage of reflective practice, the researcher is recognised as a participant as well as an observer, and the language of the paper reflects this in the use of the first person, where appropriate. Unlike a standard evaluation of a programme, this paper is concerned with the experience, rather than statistical results. Further research is under way which will provide the graduate outcomes, but that will not be concerned with the blending of the pedagogical approaches, as this is.

As a result of five years' experience in developing, delivering and revising the programme, and based upon my personal experience and that of my colleagues, I have identified three challenges that have been faced: the fundamental one of the discourse which provided initial difficulties; the necessity for interdisciplinarity in a traditionally discipline-driven area and finally some specific pedagogical issues, such as purpose, assessment issues, dealing with large classes, and curriculum development.

\section{Results}

This section is concerned with exploring the challenges that have been faced. It embodies a reflection upon what those challenges are, how they have been addressed and raises some of the complexities experienced, particularly in regard to the need for innovation interplay between pedagogies. The most significant of the challenges is that of the four-cornered pedagogy of the Social Enterprise stream. Each of the pedagogies is well-established in the educational literature, however, both the intricate interplay and the application to the Humanities, results in the creation of an innovative and creative programme. I briefly discuss the issues of the discourse of social enterprise which posed an initial problem, the need to build bridges between this new discipline and the existing fields of study and then finally examine the pedagogical approach developed and refined over the last five years.

\subsection{Discourse}

One of the core issues with the creation of the Social Enterprise stream has been the vacuum into which it had to be launched. The term was rarely used in Australia, although it has broad currency in the United Kingdom and Europe, and it has no foundational discourse within the disciplines which constitute Arts degrees. In fact, only two universities in the world offered Social Enterprise studies as part of a BA: Griffith and the University of East London. In every other instance, this is an area usually taught within Business or Management faculties, with the emphasis being laid upon Corporate Social Responsibility or Not-for-Profit organisations.

One of the primary tasks, therefore, was to determine and develop a discourse of social enterprise: what was this term to mean in this specific context? In the European arena, it appeared that "Social Enterprise" and the "Third Sector" (voluntary, community and not-for-profit social organisations) were synonymous. In recent years, the term "Fourth Sector" has emerged to describe those organisations that work under a rubric of profit-for-purpose or social purpose. Part of the brief in the development of this local discourse was certainly to include these areas (and the Industry Partners drawn from those areas were to provide the WIL placements), but it also needed to draw upon the underpinning ideas on which the practices were based and to incorporate the university's (and faculty's) missions. So we were looking to make connections between the raison d'etre of the Third (or Fourth) Sector and the University or better, the Arts Faculty.

In terms of practical pedagogy, this meant that attention needed to be paid to foundational ideas and the location of the stream within existing discourses. The foundational ideas include social justice, human rights, ethical behaviour, understanding social policy development, cultural awareness, world community and environmental issues, and third sector studies.

Theoretically, this array of issues and ideas needed to be drawn together as a single diverse discourse, in order to begin to create an understanding of the complexity of Social Enterprise. The importance of a nurturing discourse lies in the power of discourse to shape as well as to reflect the significant ideas and practices (Foucault 1970, 1972), but it also enables the practical transmission of concepts. In this instance, being able to draw upon an existing discourse would have made dealing with much of the resistance to the courses a great deal easier, however the creation of the discourse was by no means an impossible task.

What does it mean to teach "social enterprise"? At the time of implementation in 2008, the signature experience in social enterprise at Griffith University was launched into a context in which the term was largely unknown. It was not only students, but also colleagues, who had no idea what this strange beast would be. "Social Enterprise" was not used in common parlance in Australia, and some of the initial resistance encountered by the programme came from the inscrutable nature of the name. While these challenges had been faced by others (Smith, 2008; Frogett \& Chamberlayne, 2004) the context for this work was the UK where social enterprise discourse was already a part of the public sphere and familiar lexicon. In Australia, social enterprise was only beginning to 
emerge as a concept - brought to the fore somewhat fortuitously by former Federal MP Cheryl Kernot who had led the UK SKOLL Centre for Social Entrepreneurship and returned to Australia with the ideas - showcased in our own Griffith Review in May, 2009 - which was followed by a series of public lectures. In late October 2010, the Australian government established a consultation process which led to the development of the Social Enterprise Development and Investment Fund, announced in July 2011 and allocated an initial \$20million to finance social enterprise in Australia.

\subsection{Interdisciplinarity}

In dealing with the ideas that underpin the Social Enterprise stream within the academy, there are two demands for interdisciplinarity immediately apparent: the content of the actual courses and the faculty context into which they are to be taught. The call for interdisciplinarity or transdisciplinarity has been sounded for several decades within the pedagogical literature, and a range of authors have made a case for the validity of studies which ask students to think beyond the comparatively narrow bounds of specific disciplines (Brewer, 1999; Dall'Alba, 2009; Gunn, 2003; Gaff \& Wilson, 1971; Hall \&Weaver, 2001; Petrie, 1992; Silver, Howard \& Clouse, 1999; Woods, 2007).

The content of the stream ranges from the initial compulsory offerings of Academic Writing and the Introduction to Social Enterprise (which teaches a range of topics from social justice, human rights, social policy, environmental and cultural awareness, to the examination of the Third Sector, community, voluntary and development programmes as well as an introduction to leadership and global civil society). In later years, students complete courses in Ethics and in understanding community and the workplace, in which they develop workplace skills and practices. The final year includes the WIL social enterprise placement and a final capstone project which involves the creation, planning, delivery and evaluation of a showcase event. These courses have to cross the divides between a range of disciplines from politics and policy, to social programmes and philanthropy, to management and business.

Additionally, in the School of Humanities context, there is a range of Fields of Study, each of which is broader than a single discipline. These range from the specific area of Islamic studies, to language and linguistics, socio-cultural studies, traditional fields such as history and literature, creative writing, or media, journalism and/or film studies. One of the aims of teaching students from across this wide range of interests is to find ways in which to incorporate or at least invoke their existing interests, so appeals to these disciplines needed to be embedded in the teaching of social enterprise. On the other hand, the materials, the foundational ideas themselves, tended to cross a range of disciplinary boundaries.

The challenge is to present a course which can integrate an array of disciplines, while developing a new and unfamiliar discourse. For example, consider the journalism major which is distinctive in its content but shares with social enterprise a commitment to truth, fairness and justice. Negotiating interdisciplinary boundaries - or better enveloping or complementing these boundaries - has been a core challenge of the social enterprise curriculum development. On the other hand, students undertaking a major in history or sociology are being taught to examine the world from the point of view of a specific discipline. In order to engage those students, and to make the content of the Social Enterprise stream intelligible, it is necessary to find ways that bridge between the disciplinary discourses. This demand requires the flexibility of an interdisciplinary approach.

\subsection{Specific Pedagogical Issues}

In exploring the pedagogical issues involved in the development of the Social Enterprise stream, I have identified five specific areas of which I am aware that call for further examination. These include: purpose, approach, assessments, large class management, and curriculum development. In this paper, I am primarily concerned with curriculum development, however purpose and approach have been explored to provide a context and I briefly touch upon assessments and large class management.

By purpose, I mean how is one to address the aims and objectives of the courses- why are we doing what we are doing? The social enterprise stream servesmultiple purposes. It builds upon the identified idealism of Arts students (Macleod, 2009; Macleod \& Chamberlain, 2012; Dolch et al, 2007) and develops within the students a deep sense of social conscience, and, hopefully a sense of capability (Nussbaum, 2000) as well. It has also proven to be a source of stimulus and creative production, encouraging an enterprising approach to the chosen fields of study and practice. In practical terms, it supports a Work Integrated Learning opportunity which provides the experience so often required of graduates in entering the workforce.

The approach developed draws upon understandings of the differences between surface and deep learning (Biggs, 1996, 2003; Fry, Ketteridge \& Marshall, 2003; Jackson, 1995; Ramsden, 2003). While there is a need for the 
provision of specific materials and case studies to make the issues relevant and comprehensible, the greater demand is for the development of a critical ability and a deep appreciation of a worldview that privileges those that have none. In practice, achieving the aim of problem-based learning (Betts \& Kercher, 1999; Boud \& Felleti, 1998; Boud, Cohen \& Walker 1993; Dewey, 1997; Fallows \& Steven, 2000; Kolb, 1984; Savin-Baden, 2000; Savery \& Duffy, 2001; Webb, Mennin and Schwartz, 2001) has been supported through the development of a series of resources, including the creation of workbooks which outline class activities that hone critical abilities, team exploration and articulation.

The assessments for the courses were dictated by the graduate attributes set out for the signature experience. There is a balance between team presentations and individual reflections (through a Reflective Practice Journal) in the first year, and the emphasis remains on assessing across a range of skills and competencies. One of the innovations in our first year was the introduction of wikis (cf Benmayor, 2008) as part of the course electronic platform. These created the opportunity for the further development of multi-media presentations skills, and required an extension of the blended learning (cf Wozniak, Scott\& Atkinson, 2005) format for the course. Although we suspended use of the wikis, this had been an intriguing experiment in learning and as our students have become more competent at managing IT, we have some plans to re-introduce more blended learning processes over time. That said, we are keen for our students to engage in unmediated personal communication and exchange that we see as critical to the workplace and being in the world. So there is a balance which we are seeking to strike between IT competency and fundamental skills in human communication.

Large class management always raises multiple issues, and in this case there were several that required attention. The first year course was compulsory, which raised considerable resistance, primarily because it was an innovation in the BA. Arts students simply have not had to undertake any compulsory courses before, and certainly none in a field of which they had no recognition, so the level of resistance was quite high. With 200 plus students on each of two campuses, there was also the matter of managing a group of tutors, none of whom had taught in this area before either. This was actually a supportive experience, as through the meetings and conversations among the teaching team, we were able to manage the course collectively, utilising suggestions and materials that each provided. Over time, the team approach has been developed, and has now become utilized across the first year courses as well.

Curriculum development is an ongoing issue with each of the six courses in the core stream being reviewed after each iteration and refinements introduced as a result of reflection upon practice. In our fifth year of delivery, the dossiers of readings have been revised and renewed, the assessment items scrutinized and reshaped or replaced, and the approach to the subject matter has become refined. This has taken some attention to the process of the pedagogical foundations, as well as reflexivity about delivery issues. In the next section, the four-fold foundation of the pedagogy is discussed, paying attention to how each is implemented, used in assessment and how it addresses the problems faced in the specific context of teaching social enterprise in the Bachelor of Arts.

\subsection{Pedagogical Approach}

The social enterprise signature experience in the BA in Humanities at Griffith University is predicated on a foundation of four pedagogical approaches. The four are: problem-based learning, inquiry based learning, work integrated learning and reflective practice. Over the suite of six courses that span the entirety of the degree, these four sets of principles form the foundation of student-centred learning which aims to develop graduate attributes which include a capacity for creativity and imagination; a well-developed understanding and applications of the core content of social enterprise principles such as human rights, social justice and practical change; a grounded real-world experience of the third sector; and a developed skill in reflecting upon practice, ideas and possibilities. This section explores the four pedagogies, and examines how they are used and interlinked within the course materials, delivery and assessment items.

This "four-corner" approach is one which favours deep over surface learning, process and transferable skills over narrow content, and problem-based learning in the form of experiential classwork over reiteration of texts. As the course material has to cover such diverse areas as social justice, human rights, social policy and governmentality, careers and vocations, business and third sector organizations, it is necessarily transdisciplinary (Brewer, 1999; Hall \& Weaver, 2001; Dall'Alba, 2009; Gunn, 2003; Gaff \& Wilson, 1971; Petrie, 1992; Silver, Howard \& Clouse 1999; Woods, 2007), a situation which the educational literature (and personal experience) shows to be fraught with both misunderstanding and some disdain from entrenched disciplines.

Problem-based learning (Betts \& Kercher, 1999; Boud \& Felleti, 1998; Boud, Cohen \&Walker, 1993; Dewey, 1997; Fallows \& Steven, 2000; Kolb, 1984; Savin-Baden, 2000; Savery \& Duffy, 2001; Webb, Mennin and Schwartz, 2001) is the first of the four pillars in the social enterprise signature experience. The understanding of 
Problem-based Learning that we have espoused is that by engaging students in active solution of issues or set tasks, the learning transcends that of a simple surface encounter with knowledge and becomes integrated at a deep level. The form and structure of the teaching lends itself to drawing attention to concepts and practices which can be integrated at a deep level (Biggs, 1996, 2003; Fry, Ketteridge \& Marshall, 2003; Jackson, 1995; Ramsden, 2003). While there is a need for the provision of specific materials and case studies to make the issues relevant and comprehensible, the greater demand is for the development of a critical ability and a deep appreciation of a worldview that privileges those that have none.

Throughout the six courses, students are invited to approach the large issues the courses raise through a series of problem-based assessments. In the first year, achieving the aim of problem-based learning has been tackled through the creation of workbooks which outline class activities that hone critical abilities, team exploration and articulation. In class activities are designed around setting up an issue, scenario or problem concerning social justice or community organisations, etc, for discussion, in light of the readings and the other course materials provided. In the second year, the problem provided in CCE is that of the creation of a social enterprise: a vision statement, mission, business plan, personal $\mathrm{CV}$ and business cards, leading to the group creation of a submission to a funding body on behalf of the fictive profit-for purpose venture. The final year has two phases of problem-based learning: in the first semester the placement offers an authentic experience of having to solve everyday problems in the workplace; while the capstone subject engages the whole cohort in the planning, creation, production and evaluation of a showcase event.

The second pillar is Inquiry-based learning. This is more familiar to those engaged in the Humanities under the rubric of "research", however, it is essentially the practice of requiring students to engage directly with materials, literature and resources in order to develop both an understanding of the concepts but also to gather evidence, analyse and evaluate, and to draw supported conclusions from their inquiries (Magnussen, 2000; Edelson, 1999; Jenkins and Healey, 2012; Lattas 2009). Often, inquiry- based learning has been seen as ideal in the primary and secondary levels of schooling, but Lattas (2009) has explored the ways in which this approach is becoming more popular in Higher education in the Humanities in Australia, indicating that throughout the country there has been a recognition that the research skills developed using this approach serve both academic and practical purposes.

Throughout the core stream of social enterprise courses, we have incorporated assessment items which require self-directed inquiry-based learning. These vary from the early class or group-based research tasks to the traditional essay required in one third year course, in which the student can choose some aspect of the workplace, management, interpersonal skills or even occupational health and safety to explore and analyse. For example, students have chosen to prepare presentations on such diverse issues as workplace safety or the problems arising in working with asylum seekers suffering from trauma, or the value of the surf-lifesaving clubs to the community. Over the past five years the range of topics chosen has been extremely broad, and students have been able to engage with the practices of independent research.

What becomes very interesting is the links that students make for themselves between the practices involved in inquiry-based learning and the problem-based learning tasks. These links are usually discovered by the use of the third pillar of the core stream pedagogy- reflective practice (Moon, 2004; Bradbury-Jones et al, 2010). In the Bachelor of Arts social enterprise core stream, reflective practice is specified as being intellectual recognition, response and evaluation of experience. From the initial first year course (Introduction to Social Enterprise) through to the completion of the degree, students are presented with a series of assessments designed to train them in reflection. Initially, this takes the form of a Reflective Practice Journal which is completed each week and engages with the course content and materials in a specific format. In the first year students are introduced to a rubric (the six As: Acknowledgement, Analysis, Assessment, Action, Application, Articulation) which provides them with a framework for reflection that they will use again over the course of their studies (Chamberlain, 2012). In the second year, in "Thinking Ethically", they are required to create a personal ethical statement (which is not assessed, but an exegesis, grounded in the discourse, is evaluated). During the Social Enterprise Placement in Third Year, students again maintain a Reflective Critical Practice Journal, using though expanding on the original format from first year; and the capstone Social Enterprise Project enables both an overview across the entire BA, as well as the Social Enterprise core stream.

The fourth pillar of the pedagogy is that of Work Integrated Learning (Absekyera, 2006; Bates, 2008; Orrell, 2004, Patrick et al, 2008). Griffith University's policy requirement that every school offers the possibility of a work integrated learning experience to all meant that some considerable exploration of what Humanities students want to achieve had to be undertaken. Macleod (2009) undertook a project into the value of the BA which revealed that Humanities students were highly altruistic, wanted to make a difference in the world, and wanted to have a place in the community. The decision was taken then to develop a WIL element which directly enabled 
students to have an authentic workplace experience, located in the arenas that many BA graduates gravitate towards. Apart from teaching or the public service, these were largely the Third Sector, not-for-profits and NGOs. In order to support and prepare historians, film critics, sociologists and literature majors for Work Integrated Learning, the entire core stream develops the skills needed for the workplace. From the initial exploration of current social and community issues in the First Year, through the ethical foundation and the preparation for the workplace in the second year, to the Placement in third year and the final capstone evaluation of the entire experience, students are encouraged and supported to develop the kinds of skills and capacities which they need to be work-ready.

A curious, and in Foucault's (1972) term, "unintended consequence" of the use of this four-corner pedagogical approach is the notable increase in the numbers of students going on to post-graduate studies. In combining problem-solving with inquiry skills, together with honest self-reflection and the actual experience of the workplace, students gain a level of intellectual self-confidence which enables them to tackle the next challenge.

The pedagogical approach is one which favours 'depth over surface' learning, process and transferable skills over narrow content, and problem-based learning in the form of experiential classwork over reiteration of texts. As the course material has to cover such diverse areas as social justice, human rights, social policy and governmentality, careers and vocations, business and third sector organizations, it is necessarily transdisciplinary: a situation which the educational literature (and personal experience) shows to be fraught with both misunderstanding and some disdain from entrenched disciplines. We have certainly encountered this at Griffith University. However over time, as a discourse is developed and entrenched, our Social Enterprise experience is becoming less the foreign - and more the familiar - in our Arts degree.

\section{Conclusion}

It may seem as though the four-square multiple pedagogy approach could be somewhat complex to implement; however in practice, it has been almost organic. Each of the different aspects feeds into the others, so that students who are otherwise required to only implement an Inquiry-based learning approach in their specific discipline studies practice, even within the discipline. Alternatively, the use of problem-based learning opens a space for developing autonomous learning practices which benefit the research skills that they are developing by creating an awareness of the usefulness of task setting and exploration. When, in the final year, students undertake the WIL placement, or at the capstone course in which they are required to draw together their entire degree in a public presentation, the benefits of the complex pedagogy becomes apparent. Students self-disclose an increased level of confidence and a recognition of their competence through their presentations and in the workplace.

One of the benefits of engaging in this approach is that it replicates the complexity of experience that graduates will face. In the workplace, except in rare instances, the need for research skills alone will not be prevalent. With grounding in a multifaceted approach to learning and doing, the graduate is equipped to face often complicated and diverse demands. Where there has been difficulty in 'seeing change' - we let our student 'see possibilities and opportunities' to be a part of, or lead, social change. They see, learn about it, discuss it and eventually do it for themselves thus building a bridge between what they are learning and what they can do with it, post-graduation in the 'real' world.

The BA has traditionally been the generalist degree in which a student enters in order to explore ways and means of comprehending the world, and which provides that graduate with a capacity to reason, evaluate and to have the courage to take up the leadership opportunities available to them. One of the advantages of the social enterprise core stream is that it provides a way of ensuring those who either cannot or have no desire to become 'exemplary scholars' have a stream that will support the critical practice that we expect to emerge from universities, and especially an Arts degree.

\section{References}

Abeysekera, I. (2006). Issues relating to designing a work-integrated learning program in an undergraduate accounting program and its implications for curriculum. Asia-Pacific Journal, 7(1), 7-15.

Bates, M. (2008). Work integrated curricula in university programs. Higher Education and Development, 27(4), 305-317. http://dx.doi.org/10.1080/07294360802406775

Benmayor, R. (2008). Digital Storytelling as a Signature Pedagogy for the New Humanities. Arts \& Humanities in Higher Education, 7(2), 188-204. http://dx.doi.org/10.1177/1474022208088648

Betts, G. T., \& Kercher, J. K. (1999). Autonomous learner model: Optimizing ability. Cheltenham, Australia: Hawker Brownlow Education. 
Biggs, J. (1996). Enhancing Teaching through constructive alignment. Higher Education, 32(3), 347-364. http://dx.doi.org/10.1007/BF00138871

Biggs, J. (2003). Teaching for quality learning at university (2nd ed.). Buckingham: SRHE and Open University Press.

Boud, D., Cohen, R., \& Walker, D. (1993). Using experience for learning. Buckingham, UK: Open University Press. http://dx.doi.org/10.1080/14703290701241034

Boud, D., \& Costley, C. (2007). From project supervision to advising: New concepts of the practice. Innovations in Education and Teaching International, 4(2), 119-130.

Boud, D., \& Grahame, F. (1998). The challenge of problem-based learning. London, UK: Routledge.

Bradbury-Jones, C., Coleman, D., Davies, H., Ellison, K., \& Leigh, C. (2010). Raised emotions: A critique of thePeshkin Approach to Reflection. Nurse Education Today, 30, 568-572. http://dx.doi.org/10.1016/j.nedt.2009.12.002

Brewer, G. (1999). The challenges of Interdisciplinarity. Policy Sciences, 32(4), 327-337. http://dx.doi.org/10.1023/A:1004789429396

Chamberlain, S. (2012, November). Developing Reflection: A practice framework. ACEN Conference Proceedings (pp. 26-31). Paper presented at the Proceedings of the conference of the Australian Collaborative Education Network Conference. Geelong: Victoria.

Dall'Alba, G. (2009). Learning Professional Ways of Being: Ambiguities of becoming. Educational Philosophy and Theory, 4l(1). http://dx.doi.org/10.1111/j.1469-5812.2008.00475.x

Dewey, J. (1997). Experience and Education. New York, USA: Pocket Books.

Dolch, N. A., Ernst, M., McClusky, J. E., Mirabella, R., \& Sadow, J. (2007). The Nature of Undergraduate Nonprofit Education: Models of Curriculum Delivery. Nonprofit and Voluntary Sector Quarterly, 36, 28s. http://dx.doi.org/10.1177/0899764007305058

Edelson, D. C. (1999). Addressing the Challenges of Inquiry-Based Learning through Technology and Curriculum Design. The Journal of the Learning Sciences, 8(3/4), 391-450. http://dx.doi.org/10.1080/10508406.1999.9672075

Fallows, S. J., \& Steven, C. (2000). Integrating key skills in higher education: Employability, transferable skills and learning for life. London, UK: Routledge.

Field, J., \& Leicester, M. (2000). Education across the Lifespan. New York, USA: Routledge Falmer.

Foucault, M. (1970). The Order of Things. New York, USA: Random House.

Foucault, M. (1972). The Archaeology of Knowledge. London, UK: Harper Colophon.

Frogett, L., \& Chamberlayne, P. (2004). Narratives of Social Enterprise From Biography to Practice and Policy. Qualitative Social Work, 3(1), 61-77. http://dx.doi.org/10.1177/1473325004041132

Fry, H., Ketteridge, S., \& Marshall, S. (2003). Understanding student learning. In H. Fry, S. Ketteridge, \& S. Marshall (Eds.), A handbook for teaching and learning in Higher education (pp. 9-25). London, UK: Kogan Page.

Gaff, J. G., \& Wilson, R. C. (1971). Faculty Cultures and Interdisciplinary studies. The Journal of Higher Education, 42(3), 186-201. http://dx.doi.org/10.2307/1980354

Gunn, V. (2003). Transforming subject boundaries: The interface between higher education teaching and learning theories and subject-specific knowledge. Arts and Humanities in Higher Education, 2, 265. http://dx.doi.org/10.1177/14740222030023004

Hall, P., \& Weaver, L. (2001). Interdisciplinary education and teamwork: A long and winding road. Medical Education, 35, 867-875. http://dx.doi.org/10.1046/j.1365-2923.2001.00919.x

Jackson, M. W. (1995). Skimming the surface or going deep? (Teaching and learning methods in higher education). PS: Political Science and Politics, 28(3), 512-519. http://dx.doi.org/10.2307/420321

Jenkins, M., \& Healey, M. (2012). Developing and Embedding Inquiry-Guided Learning Across an Institution. New Directions for Teaching and Learning, 129, 27-37. http://dx.doi.org/10.1002/t1.20004

Kernot, C. (2009). A Quiet Revolution. Griffith review24: Participation Society, 24, 11-27.

Kolb, D. A. (1984). Experiential learning: experience as the source of learning and development. New Jersey, 
USA: Prentice Hall.

Lattas, J. (2009). Inquiry-based Learning: A Tertiary Perspective. Agora, 44(1), 12-16.

Macleod, J. (2009). Realising the Value of the BA (internal report). School of Humanities. Griffith University, Brisbane, Queensland.

Macleod, J., \& Chamberlain, S. (2012). Practical Idealism: Social enterprise as work-integrated learning across the Humanities. Australia Pacific Journal of Cooperative Education, 13(4), 195-206.

Magnussen, L., Ishida, D., \& Itano, J. (2000). The impact of the use of inquiry-based learning as a teaching methodology on the development of Critical Thinking. Journal of Nursing Education, 39(8), 360-364.

Moon, J. (2004). A handbook of reflective and experiential learning: theory and practice. New York: Routledge Falmer.

Mullin, J. (2008). Interdisciplinary work as Professional Development: Changing the culture of teaching. Pedagogy: Critical approaches to Teaching Literature, Language, Composition and Culture, 8(3), 495-508. http://dx.doi.org/10.1215/15314200-2008-008

Nussbaum, M. (2000). Women and human development: The capabilities approach. Cambridge: Cambridge University Press. http://dx.doi.org/10.1017/CBO9780511841286

Orrell, J. (2004, July). Work-Integrated Learning programmes: Management and educational quality. Proceedings of the Australian University Quality Forum (pp. 76-80). Paper presented at the Proceedings of the conference of AUQA occasional publication. Melbourne: Victoria.

Patrick, C.-J., Peach, D., Pocknee, C., Webb, F., Fletcher, M., \& Pretto, G. (2008). The WIL [Work Integrated Learning] report: A national scoping study [Australian Learning and Teaching Council (ALTC) Final report]. Brisbane: Queensland University of Technology. Retrieved from http://www.altc.edu.au and http://www.acen.edu.au

Petrie, H. G. (1992). Interdisciplinary Education: Are we faced with insurmountable opportunities? Review of Research. Higher Education, 18, 299-333.

Ramsden, P. (2003). Learning to teach in higher education. London, UK: Routledge Falmer.

Reed-Danahey, D. (2002). Turning points and textual strategies in ethnographical writing. International Journal of Qualitative Studies in Education, 15(4), 421-425. http://dx.doi.org/10.1080/09518390210145480

Savery, J. R., \& Duffy, T. M. (2001). Problem based Learning: An instructional model and its constructivist framework. Indiana University, Bloomington: CRLT.

Savin-Baden, M. (2000). Problem-based Learning in Higher Education: Untold stories. Buckingham, UK: The Society for Research into Higher Education and Open University Press.

Silver, W. S., Howard, C. T., \& Clouse, M. L. (1999). Distinctive displays: A multidisciplinary caseplay. Journal of Management Education, 23(3), 263. http://dx.doi.org/10.1177/105256299902300304

Smith, K. (2008). Embedding enterprise education into the curriculum at a research-led university. Education+Training, 50(8/9), 713-724.

Webb, G., Mennin, S., \& Schwartz, P. (2001). Problem-based learning: Case studies, experience and practice. London, UK: Routledge.

Woods, C. (2007). Researching and developing interdisciplinary teaching: Towards a conceptual framework for classroom communication. Higher Education, 54, 853-866. http://dx.doi.org/10.1007/s10734-006-9027-3

Wozniak, H., Scott, K., \& Atkinson, S. (2005, December). The balancing act: Managing emerging issues of elearning projects at the University of Sydney. Proceedings of ASCILITE 2005: Balance, Fidelity, Mobility: maintaining the momentum (pp. 735-745). Paper presented at the Proceedings of the conference of annual conference of the Australian Society for Computers in Learning in Tertiary Education. Brisbane: Queensland.

\section{Copyrights}

Copyright for this article is retained by the author(s), with first publication rights granted to the journal.

This is an open-access article distributed under the terms and conditions of the Creative Commons Attribution license (http://creativecommons.org/licenses/by/3.0/). 